\title{
Analysis of the psychometric properties of the five-factor self-concept questionnaire (AF-5) in Spanish students during the COVID-19 lockdown
}

\author{
Félix Zurita-Ortega ${ }^{1} \cdot$ David Lindell-Postigo $^{2} \cdot$ Gabriel González-Valero $^{1}$ (1) • Pilar Puertas-Molero ${ }^{1}$. \\ Manuel Ortiz-Franco ${ }^{1}$. José Joaquín Muros ${ }^{1}$
}

Accepted: 12 May 2021

(C) The Author(s), under exclusive licence to Springer Science+Business Media, LLC, part of Springer Nature 2021

\begin{abstract}
The present research aims to analyse the psychometric properties of the AF5 questionnaire for its adaptation for use with young people during a lockdown period. Research was conducted with a sample of 534 students aged between 13 and 17 years $(\mathrm{M}=$ 14.49; $\mathrm{SD}=1.805$ ). Exploratory factor analysis was conducted using the FACTOR program and confirmatory factor analysis was conducted using the M-PLUS 7 program. Results indicate that a four-dimensional model is most appropriate for bringing together the emotional and physical dimensions. Further, 11 items were removed due to poor factor loadings. The majority of factors were directly and positively correlated $(99 \% ; p<.01)$. The data obtained supports conclusions that the AF-5 meets validity and reliability requirements for it to be considered a useful instrument for use with young people during the COVID19 lockdown period.
\end{abstract}

Keywords Self-concept $\cdot$ Youth $\cdot$ Factor analysis, psychosocial

\section{Introduction}

Self-concept has been defined in a number of ways, however, the various definitions can be summarised as an individual's knowledge and perception of themselves. Self-concept varies

Gabriel González-Valero

ggvalero@ugr.es

Félix Zurita-Ortega

felixzo@ugr.es

David Lindell-Postigo

dlindell@novaschool.es

Pilar Puertas-Molero

pilarpuertas@correo.ugr.es

Manuel Ortiz-Franco

manuelortizfranco@gmail.com

José Joaquín Muros

jjmuros@ugr.es

1 Department of Didactics of Musical, Plastic and Corporal Expression, University of Granada, Campus de Cartuja, s/n 18071, Granada, Spain

2 Teacher of Novaschool Sunland International, Carretera de Cártama Estación a Pizarra, s/n 29580, Estación de Cártama, Málaga, Spain over an individual's lifetime as they adapt to new environments and situations (Cantor \& Kihlstrom, 1987; Markus \& Wurf, 1987; O'Connor et al., 2018). It is the direct result of an interaction between the perceptions individuals hold about themselves and the perceptions others hold of them (Gecas, 1982; Murray et al., 2020; Peiffer et al., 2020; Shavelson et al., 1976), in addition to the way in which external behaviours are internalised (Bandura, 1986; Wu et al., 2019). Various versions of the theory have been applied over recent years but the most accepted version currently is that described by Shavelson et al. (1976). This conceives self-concept as a combination of five dimensions: emotional, physical, social, family and academic.

Self-concept is considered a crucial variable in education and so has been extensively researched in school settings (Peiffer et al., 2020; Shavelson et al., 1976). In fact, considerations of self and identity may negate behavioral risks (Pfeifer \& Berkman, 2018). Interest in the concept has continued to increase in more recent times. Relevant conclusions of this research includes findings of the existence of gender differences (Chui \& Wong, 2016; Fernández-Lasarte et al., 2019; Widlund et al., 2020; Wirthwein et al., 2020) and existence of a concave relationship during adolescence. Specifically, females traditionally exhibit greater self-concept in academic and affective contexts, whilst males do so in physical and 
social contexts (González-Valero et al., 2020; Marsh, 1989). Appropriate self-concept has been shown to enhance and predict achievement and teacher-engagement (Bakadorova et al., 2020; Guo et al., 2016; Kumar-Jaiswal \& Choudhuri, 2017; Musetti et al., 2019), whilst also improving self-efficacy (Zamani-alavijeh et al., 2019), being positively correlated with peer perceptions of (Ingles et al., 2017) and generating higher self-esteem (Baudson et al., 2016; Coelho et al., 2020). From a general point of view, childhood is crucial for the development of personality and identity, where personal goals, commitment, motivations and psychosocial well-being are interrelated (Pfeifer \& Berkman, 2018).

Although few studies have been published on selfconcept during the COVID-19 lockdown (Alessandri et al., 2020; González-Valero et al., 2020; Lindell-Postigo et al., 2020; Zhang et al., 2020), similar situations have been examined, where health and social concerns underlie contexts such as those relating to refugees (Akgül et al., 2019; Derman et al., 2017; Hatoss, 2012; Klimidis et al., 1994; Schmidt et al., 2008) and long-term hospital patients (Choi \& Ferro, 2018; Mishra et al., 2010). In this sense, these situations lead to lower self-concept since depression and isolation are correlated with a negative self-concept (González-Valero et al., 2020; Karatzias et al., 2019; Nasstasia et al., 2019; Van Meter et al., 2013). Conversely, a positive self-concept may buffer the psychological impact of trauma in adolescents (Wang et al., 2020).

In accordance with the theoretical precepts mentioned above (Shavelson et al., 1976), a questionnaire was created to measure the academic, family, social, physical and emotional dimensions of self-concept (García \& Musitu, 1999). This questionnaire has previously been validated in a broad range of populations (Carranza-Esteban \& Bermudez-Jaimes, 2017; Esnaola et al., 2011; García et al., 2018; Malo-Cerrato et al., 2011; Martínez-Martínez et al., 2018; Zurita-Ortega et al., 2018a; Zurita-Ortega et al., 2018b), with an english version also having been validated (García et al., 2013). Nevertheless, none of these validation studies were conducted with a population undergoing lockdown or experiencing a similar situation to that of the present crisis. This is, therefore, a great opportunity to evaluate the psychometric properties of this scale within such a population.

The COVID-19 pandemic has been shown to have not only caused physical and mental health problems (Bassi et al., 2020; De Miranda et al., 2020; Raballo et al., 2020) but to have also altered the psychosocial state of individuals and their perceptions of themselves, their families and their peers (De Figueiredo et al., 2020; Serlachius et al., 2020). In this sense, it is necessary to further investigate self-concept within a population undergoing lockdown measures, in order to uncover the actual state of affairs within this population and to be able to intervene effectively. Thus, the present research aims to assess the psychometric properties of the five-factor self- concept questionnaire (García \& Musitu, 1999) in a sample of adolescents during the COVID-19 lockdown.

\section{Method}

\section{Participants}

A total of 534 Spanish students aged between 13 and 17 years $(\mathrm{M}=14.49 ; \mathrm{SD}=1.805)$ were invited to participate $(39.7 \%$ male) in the present research. All participants were attending secondary school in Andalusia (Spain). A convenience sample was recruited from six secondary schools. A total of 534 individuals provided informed consent and were administered the questionnaires in April 2020. For inclusion, participants had to meet the criteria of being enrolled at secondary school and being aged between 13 and 17 years. Cases were excluded if they did not meet these conditions or did not fill questionnaires out correctly. Eighteen participants were excluded for failing to produce valid responses, leaving a final sample of 516. Of the aforementioned sample, 314 students attending four secondary schools participated in the analysis EFA (Exploratory Factor Analysis). 202 students attending 2 different secondary schools with similar characteristics to those of the schools in the first analysis participated in the analysis CFA (Confirmatory Factor Analysis). The sample met criteria for representativeness.

\section{Instruments}

An ad-hoc questionnaire was used to collect sociodemographic characteristics. This questionnaire recorded participants' sex (male or female) and age.

The five-factor self-concept questionnaire (AF-5) (García \& Musitu, 1999) was used to evaluate self-concept in students during the COVID-19 lockdown. This test consists of 30 questions which are assessed along a five-point Likert scale, with 1 being 'never and 5 being 'always'. Higher dimensional and overall scores indicated better self-concept. The questionnaire consists of five dimensions: academic self-concept (A$\mathrm{SC}$ ), social self-concept (S-SC), emotional self-concept (ESC), family self-concept (F-SC) and physical self-concept (P-SC). Participants are asked to respond to thirty items on a five-point Likert scale ranging from never (1) to always (5). A number of items are used to address each of the dimensions (A-SC: items 1, 6, 11, 16, 21 and 26; S-SC: items 2, 7, 12, 17, 22 and 27; E-SC: items 3, 8, 13, 18, 23 and 28; F-SC: items 4, 9, 14, 19, 24 and 29; P-SC: items 5, 10, 15, 20, 25 and 30). Internal consistency of the scale was assessed according to Cronbach's alpha, with $\alpha=0.800$ being obtained in the present study. Similar results have been previously reported by García and Musitu (1999), with a Cronbach's alpha of $\alpha=$ 0.810 being reported in this case. 


\section{Procedure}

Parents or legal guardians were informed by means of a letter prepared by the Department of Didactics of Musical, Artistic and Corporal Expression of the University of Granada. All participants were informed that data would be confidential and would only be used for scientific purposes. Questionnaires were administered online during lockdown. For this purpose, a Google form was created where the purpose of the study was stated and respondents were given the option to state their agreement to participate. Teachers informed participants of the relevant link in school during school hours. The digital platforms already being used by teachers to teach online classes were used. To avoid random responses and to control for response bias, one questionnaire item was repeated at a later stage in the questionnaire. A total of 18 questionnaires were eliminated due to incorrect completion or failure to meet inclusion criteria.

The present study adhered to the ethical research principles established by the Declaration of Helsinki (World Medical Association, 2009), ensuring anonymity and respecting the rights of participants. In addition, approval of the research was granted by the Ethics Committee of the University of Granada (1230/CEIH/2020).

\section{Statistical Analysis}

Basic descriptive coefficients (mean, dispersion, kurtosis and asymmetry) were analysed using SPSS 25.0 for Windows. Psychometric properties of the measures were examined through perusal of goodness of fit indices following exploratory factor analysis using the program FACTOR Analysis 9.3.1 (Lorenzo-Seva and Ferrando, 2006). Assessment was based on several criteria such as those recommended by Bentler (1990) and McDonald and Marsh (1990). Cronbach's alpha coefficient was examined in order to determine internal consistency of the instrument and its dimensions. M-PLUS 7 (Muthén \& Muthén, 2007) was used to conduct confirmatory factorial analysis.

EFA and CFA were conducted according to classical methods (parametric) since these analyses are based on the structure of the correlation matrix, whose nature is always quantitative, regardless of the type of variables examined. "EFA analysis was conducted via maximum likelihood extraction methods, using the polychromic correlation matrix, due to their important advantages relative to other models (Fabrigar et al., 1999). Promin oblique rotation was used following recommendations made by Lorenzo-Seva (1999), which indicate that oblique rotations (promin) are probably the best option, at least in social sciences. Rotated factor loadings were analysed in order to establish whether groups matched the underlying factors of the original scale. The number of factors extracted were verified using Horn's parallel analysis (PA). Horn (1965) and Timmerman and LorenzoSeva (2011) have proposed the AP as an empirical method based on the generation of random variables to determine the number of factors that must be retained when performing factor analysis. Finally, CFA was carried out though a structural equation model in order to verify whether the factor structure of the original scale was replicated. The Bentler-Bonett comparative index (CFI) and root mean square error of approximation (RMSEA) were calculated in order to estimate goodness of fit. The following cut-points were used to define good fit: $\mathrm{CFI}>0.95(\mathrm{Hu} \&$ Bentler, 1999) and RMSEA $<0.07$ (Steiger, 2007).

\section{Results}

\section{Descriptive Statistics and Missing Data}

Table 1 shows the descriptive findings pertaining to the AF-5 alongside results of dispersion analysis (asymmetry and kurtosis) following steps recommended by experts in the field (Schmider et al., 2010). Minimum covariance coverage was $99.1 \%$.

\section{Exploratory Factor Analysis (EFA)}

In the first part of the analysis, FACTOR Analysis 9.3.1 (Lorenzo-Seva and Ferrando, 2006) was used with a sample of 314 students. Factor analysis was conducted to develop various models, rotating data through three, four and five factors (Lorenzo-Seva and Ferrando, 2006) (Table 2).

Table 3 shows outcomes of the parallel analysis carried out in line with that described by Horn (1965), Timmerman and Lorenzo-Seva (2011). These analyses suggested the existence of three dimensions. Nonetheless, a four-dimensional model was used because the presence of emotional and physical dimensions could not be discarded. Both dimensions are of great interest in the field of social sciences.

Table 4 present results of the evaluation of the psychometric properties of the 30-item AF-5. Following examination of the loadings of all factors, it can be observed that for the 3factor model the variables V.6, V.8, V, 17 and V.30 were removed as these variables did fulfil criteria. Furthermore, in the 4-factor model, the variables V.5, V.8, V.15, V.16, V.17, V.21, V.26 and V.30 were removed for not meeting fit criteria, whilst V.10, V.22 and V27 were also removed owing to poor loading. With regard to the 5-factor model, variables V.17, V.26 and V.27 were removed. Further, factors 3 and 4 did not produce appropriate loadings and variables V.10 and V.15 did not meet fit criteria. The final scale was formed of four factors. Study researchers, therefore, selected the fourfactor model which joined the emotional and physical dimensions (V3, V13, V18, V20, V23, V25 and V28). The family 
Table 1 Descriptive statistics pertaining to the AF-5

\begin{tabular}{rrrrrrr}
\hline & Mean & \multicolumn{1}{c}{ SD } & Variance & Asymmetry & Kurtosis & Range \\
\hline V 01 & 4.01 & .856 & .733 & -.589 & -.239 & 3 \\
V 02 & 3.57 & 1.133 & 1.284 & -.352 & -.759 & 4 \\
V 03 & 2.88 & 1.011 & 1.023 & -.414 & -.629 & 4 \\
V 04 & 3.24 & 1.139 & 1.296 & -.368 & -.529 & 4 \\
V 05 & 3.66 & .990 & .981 & -.157 & -1.010 & 3 \\
V 06 & 3.93 & 1.001 & 1.002 & -.526 & -.638 & 4 \\
V 07 & 4.21 & .898 & .806 & -.997 & .208 & 3 \\
V 08 & 3.35 & 1.131 & 1.280 & -.030 & -.802 & 4 \\
V 09 & 3.93 & 1.020 & 1.040 & -.589 & -.782 & 3 \\
V 10 & 3.01 & 1.342 & 1.800 & -.032 & -1.138 & 4 \\
V 11 & 3.67 & 1.019 & 1.038 & -.277 & -.841 & 4 \\
V 12 & 3.68 & 1.210 & 1.465 & -.600 & -.602 & 4 \\
V 13 & 3.32 & 1.191 & 1.418 & -.503 & -.650 & 4 \\
V 14 & 4.07 & 1.048 & 1.099 & -.956 & .187 & 4 \\
V 15 & 3.42 & 1.227 & 1.505 & -.409 & -.820 & 4 \\
V 16 & 3.68 & .964 & .929 & -.233 & -.669 & 4 \\
V 17 & 3.99 & 1.078 & 1.163 & -1.028 & .482 & 4 \\
V 18 & 3.79 & 1.116 & 1.246 & -.815 & .077 & 4 \\
V 19 & 4.39 & .998 & .995 & -1.531 & 1.221 & 4 \\
V 20 & 3.17 & 1.297 & 1.682 & -.217 & -1.014 & 4 \\
V 21 & 4.01 & .947 & .896 & -.759 & -.026 & 4 \\
V 22 & 3.21 & 1.230 & 1.513 & -.353 & -.748 & 4 \\
V 23 & 3.57 & 1.269 & 1.609 & -.565 & -.692 & 4 \\
V 24 & 3.99 & 1.142 & 1.303 & -1.062 & .302 & 4 \\
V 25 & 3.53 & 1.192 & 1.421 & -.430 & -.653 & 4 \\
V 26 & 3.85 & 1.046 & 1.094 & -.552 & -.548 & 4 \\
V 27 & 3.71 & 1.135 & 1.288 & -.526 & -.578 & 4 \\
V 28 & 3.11 & 1.153 & 1.328 & -.395 & -.596 & 4 \\
V 29 & 4.27 & .977 & .955 & -1.055 & .052 & 4 \\
V 30 & 2.97 & 1.186 & 1.407 & -.078 & -.786 & 4 \\
\hline & & & & & & \\
\hline
\end{tabular}

dimension comprised V2, V7 and V12, and the social component consisted of V1, V6 and V11. The researchers considered it important to retain the two items which loaded on both the physical and emotional dimensions.

Table 5 shows the rotated four factor matrix. Examination of the Bartlett statistic [1.980.2 $(\mathrm{df}=435 ; \mathrm{p}=0.000)]$ and
Table 3 Parallel Analysis (PA) based on minimum rank factor analysis

\begin{tabular}{|c|c|c|c|}
\hline Variable & $\begin{array}{l}\text { Real-data \% } \\
\text { of variance }\end{array}$ & $\begin{array}{l}\text { Mean of random } \\
\text { \% of variable }\end{array}$ & $\begin{array}{l}95 \text { percentile of } \\
\text { random \% of variance }\end{array}$ \\
\hline 1 & $28.6^{*}$ & 8.7 & 9.5 \\
\hline 2 & $12.6^{*}$ & 8.0 & 8.6 \\
\hline 3 & $9.8^{*}$ & 7.4 & 7.9 \\
\hline 4 & 6.6 & 6.9 & 7.3 \\
\hline 5 & 6.6 & 6.5 & 6.9 \\
\hline 6 & 5.4 & 6.1 & 6.5 \\
\hline 7 & 4.2 & 5.7 & 6.1 \\
\hline 8 & 3.3 & 5.4 & 5.7 \\
\hline 9 & 3.1 & 5.1 & 5.4 \\
\hline 10 & 2.7 & 4.7 & 5.0 \\
\hline 11 & 2.4 & 4.4 & 4.7 \\
\hline 12 & 2.3 & 4.1 & 4.4 \\
\hline 13 & 1.9 & 3.8 & 4.1 \\
\hline 14 & 1.7 & 3.5 & 3.8 \\
\hline 15 & 1.5 & 3.2 & 3.5 \\
\hline 16 & 1.4 & 2.9 & 3.2 \\
\hline 17 & 1.3 & 2.7 & 2.9 \\
\hline 18 & 1.1 & 2.4 & 2.7 \\
\hline 19 & 0.8 & 2.1 & 2.4 \\
\hline 20 & 0.7 & 1.8 & 2.1 \\
\hline 21 & 0.6 & 1.6 & 1.8 \\
\hline 22 & 0.6 & 1.3 & 1.6 \\
\hline 23 & 0.5 & 1.0 & 1.2 \\
\hline
\end{tabular}

outcomes of the Kaiser-Meyer-Olkin (KMO) test (0.859) suggested that model fit was acceptable. The four factors extracted explained $50.5 \%$ of the total variance. Further, the CFI (comparative fit index) was 0.99 , goodness of fit index (GFI) was 0.95, AGFI was 0.94, RMSEA (root mean square error of approximation) was 0.029 and the root mean squared residual (RMSR) was 0.067 . All of these values indicate acceptable fit. In general, a good fit of the model to the empirical data was observed. The reliability coefficient for the overall questionnaire was 0.826 . When broken down into the four dimensions, reliability coefficients were as followed: family

Table 2 Model fit statistics pertaining to model rotated around three, four and five factors

\begin{tabular}{|c|c|c|c|c|c|c|c|c|}
\hline & Bartlett & KMO & Variance & CFI & GFI & AGFI & RMSEA & RMSR \\
\hline Factor Three & $\begin{array}{l}1.980 .2 \\
\quad(\mathrm{df}=435 ; p=0.000)\end{array}$ & 0.859 & $43.6 \%$ & 0.97 & 0.94 & 0.92 & 0.047 & 0.079 \\
\hline $\begin{array}{l}\text { Factor } \\
\text { Four }\end{array}$ & $\begin{array}{l}1.980 .2 \\
\quad(d f=435 ; p=0.000)\end{array}$ & 0.859 & $50.5 \%$ & 0.99 & 0.95 & 0.94 & 0.029 & 0.067 \\
\hline $\begin{array}{r}\text { Factor } \\
\text { Five }\end{array}$ & $\begin{array}{l}1.980 .2 \\
\quad(d f=435 ; p=0.000)\end{array}$ & 0.859 & $60.7 \%$ & 0.99 & 0.97 & 0.96 & 0.016 & 0.060 \\
\hline
\end{tabular}


Table 4 Rotated factor matrix

\begin{tabular}{|c|c|c|c|c|c|c|c|c|c|c|c|c|}
\hline & \multicolumn{5}{|c|}{ Five factors } & \multicolumn{4}{|c|}{ Four factors } & \multicolumn{3}{|c|}{ Three factors } \\
\hline & F1 & F2 & F3 & F4 & F5 & F1 & F2 & F3 & F4 & F1 & F2 & F3 \\
\hline V 01 & & & 0.793 & & & & & & 0.611 & & 0.469 & \\
\hline V 02 & & & & 0.860 & & & & 0.868 & & & 0.779 & \\
\hline V 03 & & 0.659 & & & & & 0.453 & & & 0.456 & & \\
\hline V 04 & & & & & 0.345 & 0.302 & & & & & & 0.352 \\
\hline V 05 & & & 0.476 & & & & & & & & 0.501 & \\
\hline V 06 & & & 0.808 & & & & & & 0.676 & & & \\
\hline V 07 & & & 0.561 & & & & & 0.609 & & & 0.725 & \\
\hline V 08 & & -0.399 & & & & & & & & & & \\
\hline V 09 & & & & & 0.600 & 0.475 & & & & & & 0.454 \\
\hline V 10 & & 0.338 & & & & & & 0.393 & & & 0.388 & \\
\hline V 11 & & & 0.861 & & & & & & 0.600 & & 0.604 & \\
\hline V 12 & & & & 0.818 & & & & 0.790 & & & 0.659 & \\
\hline V 13 & & 0.680 & & & & & 0.483 & & & 0.467 & & \\
\hline V 14 & & & & & 0.608 & 0.712 & & & & & & 0.714 \\
\hline V 15 & 0.427 & & & & & & & & & & & 0.365 \\
\hline V 16 & 0.738 & & & & & & & & & & & 0.567 \\
\hline \multicolumn{13}{|l|}{ V 17} \\
\hline V 18 & & 0.588 & & & & & 0.756 & & & 0.716 & & \\
\hline V 19 & & & & & 0.744 & 0.657 & & & & & & 0.438 \\
\hline V 20 & & 0.418 & & & & & 0.467 & & & 0.450 & & \\
\hline V 21 & 0.687 & & & & & & & & & & & 0.707 \\
\hline V 22 & & 0.431 & & & & & 0.553 & & & 0.571 & & \\
\hline V 23 & & 0.623 & & & & & 0.659 & & & 0.608 & & \\
\hline V 24 & & & & & 0.857 & 0.895 & & & & & & 0.717 \\
\hline V 25 & & & & & & & 0.545 & & & 0.550 & & \\
\hline V 26 & 0.866 & & & & & & & & & & & 0.624 \\
\hline V 27 & & & & & & & 0.409 & & & 0.422 & & \\
\hline V 28 & & 0.797 & & & & & 0.690 & & & 0.707 & & \\
\hline V 29 & & & & & 0.918 & 0.959 & & & & & & 0.696 \\
\hline V 30 & 0.518 & & & & & & & & & & & \\
\hline
\end{tabular}

( $\alpha=0.779)$, emotional-physical $(\alpha=0.796)$, academic $(\alpha=$ $0.826)$ and social $(\alpha=0.804)$.

\section{Confirmatory Factor Analysis (CFA)}

In the second part of the study, the MPLUS-7 programme was used to conduct confirmatory factor analysis with a sample of 202 participants who were not included in the prior analysis. Figure 1 shows the outcome of confirmatory factor analysis of the adapted version of the AF5. RMSEA (0.074), CFI (0.93), TLI (0.91) and SRMR (0.09) values all suggest acceptable model fit.

Table 6 shows the correlations produced between the different dimensions of the questionnaire. A medium strength correlation is observed between family self-concept and emotional-physical self-concept $(\mathrm{r}=.264, p=.001)$, and between family self-concept and social self-concept $(r=.330$, $p=.001)$. Moreover, there was a moderate correlation $(\mathrm{r}=.376, p=.001)$ between the social and academic dimensions.

$$
* P<0.05 ; * * P<0.01
$$

\section{Discussion and Conclusions}

Given the issues that have arisen due to the COVID-19 pandemic in the context of Physical Education, it is essential that questionnaires are available which provide real and reliable data about the experiences of young during the coronavirus lockdown. Thus, the main aim of the present study was to 
Table 5 Rotated factor matrix for the four-factor model

\begin{tabular}{|c|c|c|c|c|}
\hline & F1 (FM) & F2 (EM-F) & F3 (AC) & F4 (SC) \\
\hline V 04 & 0.302 & & & \\
\hline V 09 & 0.475 & & & \\
\hline V 14 & 0.712 & & & \\
\hline V 19 & 0.657 & & & \\
\hline V 24 & 0.895 & & & \\
\hline V 29 & 0.959 & & & \\
\hline V 03 & & 0.453 & & \\
\hline V 13 & & 0.483 & & \\
\hline V 18 & & 0.756 & & \\
\hline V 20 & & 0.467 & & \\
\hline V 23 & & 0.659 & & \\
\hline V 25 & & 0.545 & & \\
\hline V 28 & & 0.690 & & \\
\hline V 02 & & & 0.868 & \\
\hline V 07 & & & 0.609 & \\
\hline V 12 & & & 0.790 & \\
\hline V 01 & & & & 0.611 \\
\hline V 06 & & & & 0.676 \\
\hline V 11 & & & & 0.600 \\
\hline Alpha Cronbach $\alpha=0.826$ & $\alpha=0.799$ & $\alpha=0.796$ & $\alpha=0.826$ & $\alpha=0.804$ \\
\hline
\end{tabular}

analyse the psychometric properties of the AF5 questionnaire in order to paint a clear picture about individuals' perceptions about themselves in relation to five dimensions: academic, social, emotional, family and physical. Furthermore, through this process, the present study investigated the adaptation and application of this measure with young people.

The present sample enabled hugely novel data to be gathered in comparison to other studied samples given the fact that it pertains to a previously unknown context that of government enforced confinement. This is of further interest because such measures could be repeated in the future.

The AF5 is based on an initial model that is made up of five dimensions (García \& Musitu, 1999). It has been adapted to different contexts and populations including those involving students and videogames (Martínez-Martínez et al., 2018), judokas (Zurita-Ortega et al., 2018a), undergraduates and religion (Zurita-Ortega et al., 2018b) or adults and adolescents (Malo-Cerrato et al., 2011). All of these contexts exhibited important adaptations to all or some of the dimensions of self-concept.

The present study examined a number of different models, analyzing the properties of models with three, four and five dimensions. The four-dimension model produced the most appropriate values and the strongest relationships with relevant indicators. The present model joined together both the emotional and physical components, which is in contrast to that seen in other studies on the topic. Indeed, these other studies removed the family component due to poor fit (Tomás \& Oliver, 2004; Esnaola et al., 2011). As previously explained by a number of researchers, the family component is often removed due to divergent responses as family is not highly regarded in adulthood. However, the present study combined both the emotional and physical components since physical activity engagement is highly associated with emotions (Cho, 2020; Padial-Ruz et al., 2020). Given that physical activity outside of the home was forbidden, two items were found to be related to the emotional dimension.

With regard to Cronbach's alpha and scaling factors, results were satisfactory (Duhacheck \& Iacobucci, 2004). This confirms that the measure is valid and reliable for estimating the self-concept of young people during a lockdown, reducing the original scale of 30 items to and adapted version with 19 relevant items.

Moreover, the family and emotional-physical dimensions of the original version of the questionnaire were found to be the most robust in the present study as all relevant factors were coherent with no items, therefore, having to be removed. This is supported by findings of studies conducted by Bachner et al. (2020) and Ng et al. (2020) who stated that family is a decisive element during potentially harmful situations. In this way, given that in the present study setting young individuals were confined at home with their guardians, family took on a critical role. 


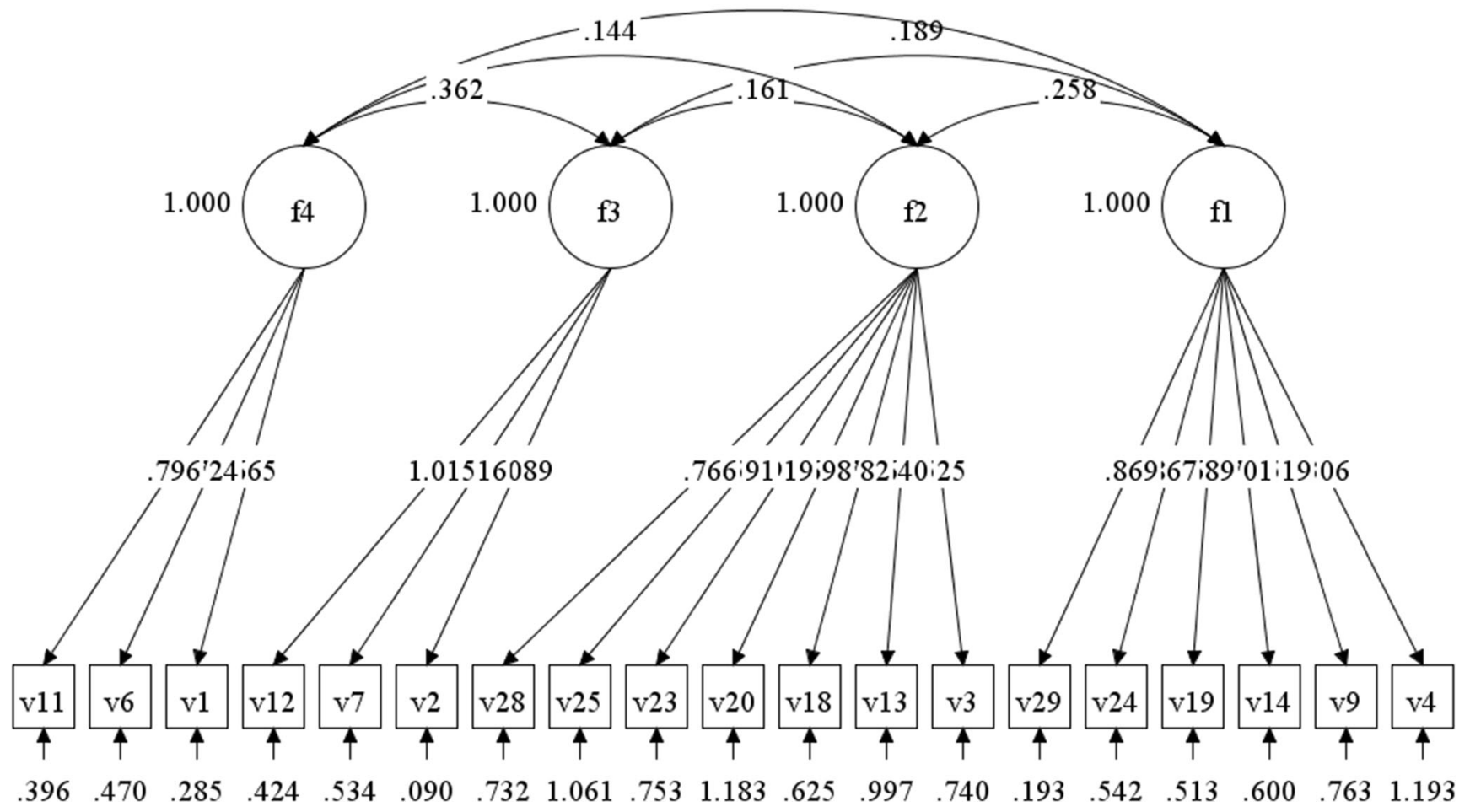

Fig. 1 Confirmatory factor analysis of the adapted version of the AF5

Furthermore, social and academic components were reduced with up to half of the questions pertaining to these components being eliminated. This is logical given that social relations and academic aspects were impeded during the lockdown period.

Additionally, it can be confirmed that the four dimensions of the present model showed acceptable adjustment, in addition to suitable reliability.

There was a moderate positive association between family self-concept and emotional-physical/social selfconcept. Individuals' home environment may explain this since a higher family self-concept strengthens emotions and social relations. In this way, family becomes a pivotal element of student's happiness, ability to relate socially and engagement in physical activity ( $\mathrm{Ng}$ et al., 2020; Verrastro et al., 2020; Villarejo et al., 2020). There was

Table 6 Correlations between the different dimensions of the questionnaire administered during lockdown

\begin{tabular}{lllll}
\hline & AFM & AEMFIS & ASO & AAC \\
\hline AFM & 1 & $.264^{* *}$ & $.330^{* *}$ & $.198^{*}$ \\
AEMFIS & & 1 & .123 & $.196^{*}$ \\
ASO & & 1 & $.376^{* *}$ \\
AAC & & & & 1 \\
\hline
\end{tabular}

also a moderate positive association between social and academic components. Such outcomes have also been reported by Ehm et al. (2019), who point out that high achievement results in better socialisation.

With regard to the methodology, the present analysis supports the use of a general measure of self-concept in different populations, although some limitations should be acknowledged. Firstly, a non-probabilistic sample was used and results, therefore, cannot be extrapolated to the whole Spanish population. Secondly, there was a low response rate from parents/guardians which limited the number of minors participating in the present study.

In conclusion, the examined measure was found to be valid and so is appropriate for use with young people during a lockdown.

Furthermore, the data also have some practical implications. Firstly, consistent with the theoretical groundings of the construct, self-concept is made up of five dimensions. Interventions targeting teaching should be directed towards potential virtual settings and encourage positive experiences in Physical Education. In this way, Physical Education may foster positive motivational patterns and enable engagement in physical activity. Thus, this version of the AF5 is recommended for use in other pandemic situations or health and social contexts similar to the COVID-19 pandemic. The results of the present study enable governmental and educational institutions to better understand the issues faced by the 
population and intervene effectively to address or prevent relevant psychosocial disorders.

Lastly, future research should delve deeper into the types of physical activity engaged in, in order to establish the way in which engagement may impact each of the dimensions of selfconcept. It would also be useful to establish differences according to other relevant variables (e.g. gender, educational level).

In summary, results of the present research support the use of the AF5, in a four-dimensional format, as a valid and reliable test for examining self-concept in youth during a lockdown.

Authors' Contributions Conceptualization, F.Z.O., D.L., G.G.V., P.P.M., M.O.F. and J.J.M.M.; methodology, F.Z.O., G.G.V. and J.J.M.M.; software, F.Z.O. and J.J.M.M.; validation, F.Z.O., G.G.V. and J.J.M.M.; formal analysis, F.Z.O.; investigation, D.L., G.G.V., P.P.M. and M.O.F.; resources, F.Z.O.; data curation, F.Z.O., P.P.M.; writingoriginal draft preparation, F.Z.O., D.L. and P.P.M.; writing-review and editing, F.Z.O., D.L., G.G.V., P.P.M., M.O.F. and J.J.M.M.; supervision, F.Z.O., G.G.V. and J.J.M.M. All authors have read and agreed to the published version of the manuscript.

Data Availability The data is available to the editors.

Code Availability Not applicable.

\section{Declarations}

Conflicts of Interest/Competing Interests The authors declare no conflict of interest.

\section{References}

Akgül, S., Hüsnü, Ș., Derman, O., Özmert, E., Bideci, A., \& Hasanoğlu, E. (2019). Mental health of Syrian refugee adolescents: How far have we come? Turkish Journal of Pediatrics, 61(6), 839-845. https://doi.org/10.24953/turkjped.2019.06.003.

Alessandri, G., De Longis, E., Golfieri, F., \& Crocetti, E. (2020). Can self-concept clarity protect against a pandemic? A daily study on self-concept clarity and negative affect during the COVID-19 outbreak. Identity, 1-14. https://doi.org/10.1080/15283488.2020. 1846538

Bachner, J., Sturm, D. J., Haug, S., \& Demetriou, Y. (2020). Multi-level validation of the German physical activity self-efficacy scale in a sample of female sixth-graders. BMC Public Health, 20(1). https:// doi.org/10.1186/s12889-020-09096-4.

Bakadorova, O., Lazarides, R., \& Raufelder, D. (2020). Effects of social and individual school self-concepts on school engagement during adolescence. European Journal of Psychology of Education, 35(1), 73-91. https://doi.org/10.1007/s10212-019-00423-x.

Bandura, A. (1986). Social foundations of thought and action: A social cognitive theory. Prentice-Hall.

Bassi, M., Negri, L., Delle Fave, A., \& Accardi, R. (2020). The relationship between post-traumatic stress and positive mental health symptoms among health workers during COVID-19 pandemic in Lombardy, Italy. Journal of Affective Disorders, 280, 1-6. https:// doi.org/10.1016/j.jad.2020.11.065.
Baudson, T. G., Weber, K. E., \& Freund, P. A. (2016). More than only skin deep: Appearance self-concept predicts most of secondary school students' self-esteem. Frontiers in Psychology, 7, 1568. https://doi.org/10.3389/fpsyg.2016.01568.

Bentler, P. M. (1990). Comparative fit indexes in structural models. Psychological Bulletin, 107(2), 238-246. https://doi.org/10.1037/ 0033-2909.107.2.238.

Cantor, N., \& Kihlstrom, J. F. (1987). Personality and social intelligence. Prentice-Hall.

Carranza-Esteban, R. F., \& Bermudez-Jaimes, M. E. (2017). Psychometric analysis of Garcia and Musitu's AF5 self-concept scale on college students in Tarapoto (Peru). Interdisciplinaria, 34(2), 459-472.

Cho, O. (2020). Impact of physical education on changes in students' emotional Competence: A Meta-analysis. International journal of sports medicine. In-Press. DOI:https://doi.org/10.1055/a-11925812.

Choi, C., \& Ferro, M. A. (2018). Comparing self-concept among youth currently receiving inpatient versus outpatient mental health services. Journal of the Canadian Academy of Child and Adolescent Psychiatry, 27(1), 69-74.

Chui, W. H., \& Wong, M. Y. H. (2016). Gender differences in happiness and life satisfaction among adolescents in Hong Kong: Relationships and self-concept. Social Indicators Research, 125(3), 1035-1051. https://doi.org/10.1007/s11205-015-0867-z.

Coelho, V. A., Bear, G. G., \& Bras, P. (2020). A multilevel analysis of the importance of school climate for the trajectories of students' selfconcept and self-esteem throughout the middle school transition. Journal of Youth and Adolescence. https://doi.org/10.1007/ s10964-020-01245-7.

De Figueiredo, C. S., Sandre, P. C., Portugal, L. C. L., Mázala-deOliveira, T., da Silva Chagas, L., Raony, Í., et al. (2020). COVID19 pandemic impact on children and adolescents' mental health: Biological, environmental, and social factors. Progress in NeuroPsychopharmacology and Biological Psychiatry, 110171. https:// doi.org/10.1016/j.pnpbp.2020.110171.

De Miranda, D. M., da Silva Athanasio, B., de Sena Oliveira, A. C., \& Silva, A. C. S. (2020). How is COVID-19 pandemic impacting mental health of children and adolescents?. International Journal of Disaster Risk Reduction, 101845. https://doi.org/10.1016/j.ijdrr. 2020.101845.

Derman, O., Akgül, S., Ataman, E., Ceren, M., Ozmert, E., Bideci, A., et al. (2017). The rise of a hostile adolescent population: The Syrian refugee problem. Adolescent Psychiatry, 7(2), 83-88. https://doi. org/10.2174/2210676607666170620121522.

Duhacheck, A., \& Iacobucci, D. (2004). Alpha's standard error (ASE): An accurate and precise confidence interval estimate. Journal of Applied Psychology, 89(5), 792-808. https://doi.org/10.1037/ 0021-9010.89.5.792.

Ehm, J. H., Hasselhorn, M., \& Schmiedek, F. (2019). Analyzing the developmental relation of academic self-concept and achievement in elementary school children: Alternative models point to different results. Developmental Psychology, 55(11), 2336-2351. https://doi. org/10.1037/dev0000796.

Esnaola, I., Rodríguez, A., \& Goñi, E. (2011). Propiedades psicométricas del cuestionario de Autoconcepto AF5. Anales de Psicologia, 27(1), $109-117$.

Fabrigar, L. R., Wegener, D. T., MacCallum, R. C., \& Strahan, E. J. (1999). Evaluating the use of exploratory factor analysis in psychological research. Psychological Methods, 4(3), 272-299. https://doi. org/10.1037/1082-989X.4.3.272.

Fernández-Lasarte, O., Goñi, E., Camino, I., \& Zubeldia, M. (2019). School adjustment and academic self-concept in secondary education. Revista de Investigación Educativa, 37(1), 163-179. https:// doi.org/10.6018/rie.37.1.308651. 
García, F., \& Musitu, G. (1999). AF5: Autoconcepto Forma 5. TEA Ediciones.

García, F., Gracia, E., \& Zeleznova, A. (2013). Validation of the English version of the five-factor self-concept questionnaire. Psicothema, 25(4), 549-555. https://doi.org/10.7334/psicothema2013.33.

García, F., Martínez, I., Balluerka, N., Cruise, E., García, Ó. F., \& Serra, E. (2018). Validation of the five-factor self-concept questionnaire AF5 in Brazil: Testing factor structure and measurement invariance across language (Brazilian and Spanish), gender and age. Frontiers in Psychology, 9(1), 2250. https://doi.org/10.3389/fpsyg.2018. 02250.

Gecas, V. (1982). The self-concept. Annual Review of Sociology, 8(1), 133. https://doi.org/10.1146/annurev.so.08.080182.000245.

González-Valero, G., Zurita-Ortega, F., Lindell-Postigo, D., Conde-Pipó, J., Grosz, W. R., \& Badicu, G. (2020). Analysis of self-concept in adolescents before and during COVID-19 lockdown: Differences by gender and sports activity. Sustainability, 12(18), 7792. https://doi. org $/ 10.3390 /$ su 12187792 .

Guo, J., Nagengast, B., Marsh, H. W., Kelava, A., Gaspard, H., Brandt, H., et al. (2016). Probing the unique contributions of self-concept, task values, and their interactions using multiple value facets and multiple academic outcomes. AERA Open, 2(1). https://doi.org/10. $1177 / 2332858415626884$.

Hatoss, A. (2012). Where are you from? Identity construction and experiences of "othering» in the narratives of Sudanese refugeebackground Australians. Discourse \& Society, 23(1), 47-68. https://doi.org/10.1177/0957926511419925.

Horn, J. L. (1965). A rationale and test for the number of factors in factor analysis. Psychometrika, 30(2), 179-185. https://doi.org/10.1007/ bf02289447.

Hu, L., \& Bentler, P. M. (1999). Cutoff criteria for fit indexes in covariance structure analysis: Conventional criteria versus new alternatives. Structural Equation Modeling, 6, 1-55. https://doi.org/10. 1080/10705519909540118.

Ingles, C. J., Aparisi, D., Delgado, B., Torregrosa, M. S., \& GarcíaFernández, J. M. (2017). Sociometric types and academic selfconcept in adolescents. Psicothema, 29(4), 496-501. https://doi. org/10.7334/psicothema2016.54.

Karatzias, T., Hyland, P., Bradley, A., Fyvie, C., Logan, K., Easton, P., et al. (2019). Is self-compassion a worthwile therapeutic target for ICD-11 complex PTSD (CPTSD)? Behavioural and Cognitive Psychotherapy, 47(3), 257-269. https://doi.org/10.1017/ S1352465818000577.

Klimidis, S., Minas, I. H., \& Ata, A. W. (1994). Immigrant status and gender effects on psychopathology and self-concept in adolescents: a test of the migration-morbidity hypothesis. Comprehensive Psychiatry, 35(5), 393-404. https://doi.org/10.1016/0010-440x(94) 90281-x.

Kumar-Jaiswal, S., \& Choudhuri, R. (2017). Academic self concept and academic achievement of secondary school students. American Journal of Educational Research, 5(10), 1108-1113. https://doi. org/10.12691/education-5-10-13.

Lindell-Postigo, D., Zurita-Ortega, F., Ortiz-Franco, M., \& GonzálezValero, G. (2020). Cross-sectional study of self-concept and gender in relation to physical activity and martial arts in Spanish adolescents during the COVID-19 lockdown. Education Sciences, 10(8), 210. https://doi.org/10.3390/educsci10080210.

Lorenzo-Seva, U. (1999). Promin: A method for oblique factor rotation. Multivariate Behavioral Research, 34, 347-356. https://doi.org/10. 1207/S15327906MBR3403_3.

Lorenzo-Seva, U., \& Ferrando, P. J. (2006). FACTOR: A computer program to fit the exploratory factor analysis model. Behavior research methods, 38(1), 88-91.

Malo-Cerrato, S., Bataller-Sallent, S., Casas-Aznar, F., Gras-Pérez, M. E., \& González-Carrasco, M. (2011). Psychometric analysis of the
AF5 multidimensional scale of self-concept in a sample of adolescents and adults in Catalonia. Psicothema, 23(4), 871-878.

Markus, H. R., \& Wurf, E. (1987). The dynamic self-concept: A social psychological perspective. Annual Review of Psychology, 38, 299 337.

Marsh, H. W. (1989). Age and sex effects in multiple dimensions of selfconcept: Preadolescence to early adulthood. Journal of Educational Psychology, 81(3), 417-430. https://doi.org/10.1037/0022-0663.81. 3.417.

Martínez-Martínez, A., Zurita-Ortega, F., Chacón-Cuberos, R., EspejoGarcés, T., Castro-Sanchez, M., \& Pérez-Cortés, A. J. (2018). Psychometric analysis and adaptation of the self-concept test (form 5) on university students who play video games frequently. Revista Iberoamericana de Diagnóstico y Evaluación Psicológica, 4(49), 77-86. https://doi.org/10.21865/RIDEP49.4.06.

McDonald, R. P., \& Marsh, H. W. (1990). Choosing a multivariate model: Noncentrality and goodness of fit. Psychological Bulletin, 107(2), 247-255. https://doi.org/10.1037/0033-2909.107.2.247.

Mishra, S. K., Mishra, B. R., Mishra, S., Verma, P. K., \& Praharaj, S. K. (2010). Hospital dependency: An existing concept. Psychiatria Danubina, 22(4), 548-549.

Murray, R. M., Sabiston, C. M., Coffee, P., \& Kowalski, K. C. (2020). Strengthening the relationship between physical activity and physical self-concept: The moderating effect of controllable attributions. Psychology of Sport and Exercise, 52, 101828. https://doi.org/10. 1016/j.psychsport.2020.101828.

Musetti, A., Eboli, G., Cavallini, F., \& Corsano, P. (2019). Social relationships, self-esteem, and loneliness in adolescents with learning disabilities. Clinical Neuropsychiatry, 16(4), 165-172.

Muthén, L. K., \& Muthén, B. O. (2007). Mplus User's Guide (6th ed.). Muthén \& Muthén.

Nasstasia, Y., Baker, A. L., Lewin, T. J., Halpin, S. A., Hides, L., Kelly, B. J., \& Callister, R. (2019). Differential treatment effects of an integrated motivational interviewing and exercise intervention on depressive symptom profiles and associated factors: A randomised controlled cross-over trial among youth with major depression. Journal of Affective Disorders, 259, 413-423. https://doi.org/10. 1016/j.jad.2019.08.035.

Ng, K. W., Sudeck, G., Marques, A., Borraccino, A., Boberova, Z., Vasickova, J., Tesler, R., et al. (2020). Associations between physical activity and perceived school performance of young adolescents in health behavior in school-aged children countries. Journal of Physical Activity \& Health, 17(7), 698-708. https://doi.org/10. 1123/jpah.2019-0522.

O'Connor, C., Kadianaki, I., Maunder, K., \& McNicholas, F. (2018). How does psychiatric diagnosis affect young people's self-concept and social identity? A systematic review and synthesis of the qualitative literature. Social Science \& Medicine, 212, 94-119. https:// doi.org/10.1016/j.socscimed.2018.07.011.

Padial-Ruz, R., Perez-Turpin, J. A., Cepero-Gonzalez, M., \& ZuritaOrtega, F. (2020). Effects of physical self-concept, emotional isolation, and family functioning on attitudes towards physical education in adolescents: Structural equation analysis. International Journal of Environmental Research and Public Health, 17(1), 94. https://doi. org/10.3390/ijerph17010094.

Peiffer, H., Ellwart, T., \& Preckel, F. (2020). Ability self-concept and self-efficacy in higher education: An empirical differentiation based on their factorial structure. PLoS One, 15(7), e0234604. https://doi. org/10.1371/journal.pone.0234604.

Pfeifer, J. H., \& Berkman, E. T. (2018). The development of self and identity in adolescence: Neural evidence and implications for a value-based choice perspective on motivated behavior. Child Development Perspectives, 12(3), 158-164. https://doi.org/10. 1111/cdep.12279.

Raballo, A., Poletti, M., Valmaggia, L., \& McGorry, P. D. (2020). Editorial perspective: Rethinking child and adolescent mental health 
care after COVID-19. Journal of Child Psychology and Psychiatry, INPRESS. https://doi.org/10.1111/jcpp.13371.

Schmider, E., Ziegler, M., Danay, E., Beyer, L., \& Bühner, M. (2010). Is it really robust? Reinvestigating the robustness of ANOVA against violations of the normal distribution assumption. Meythodology, 6, 147-151. https://doi.org/10.1027/1614-2241/a000016.

Schmidt, M., Kravic, N., \& Ehlert, U. (2008). Adjustment to trauma exposure in refugee, displaced, and non-displaced Bosnian women. Archives of Women's Mental Health, 11(4), 269-276. https://doi. org/10.1007/s00737-008-0018-5.

Serlachius, A., Badawy, S. M., \& Thabrew, H. (2020). Psychosocial challenges and opportunities for youth with chronic health conditions during the COVID-19 pandemic. JMIR Pediatrics and Parenting, 3(2), e23057. https://doi.org/10.2196/23057.

Steiger, J. H. (2007). Understanding the limitations of global fit assessment in structural equation modeling. Personality and Individual Differences, 42, 893-898. https://doi.org/10.1016/j.paid.2006.09. 017.

Shavelson, R. J., Hubner, J. J., \& Stanton, G. C. (1976). Self-concept, validation of construct interpretations. Review of Educational Research, 46(3), 407-441. https://doi.org/10.3102/ 00346543046003407.

Timmerman, M. E., \& Lorenzo-Seva, U. (2011). Dimensionality assessment of ordered Polytomous items with parallel analysis. Psychological Methods, 16, 209-220. https://doi.org/10.1037/ a0023353.

Tomás, J. M., \& Oliver, A. (2004). Confirmatory factor analysis of a Spanish multidimensional scale of self-concept. Revista Interamericana de Psicología, 38(2), 285-293.

Van Meter, A. R., Henry, D. B., \& West, A. E. (2013). What goes up must come down: The burden of bipolar depression in youth. Journal of Affective Disorders, 150(3), 1048-1054. https://doi.org/ 10.1016/j.jad.2013.05.039.

Verrastro, V., Ritella, G., Saladino, V., Pistella, J., Baiocco, R., \& Fontanesi, L. (2020). Personal and family correlates to happiness amongst Italian children and pre-adolescents. International Journal of Emotional Education, 12(1), 48-64.

Villarejo, S., Martinez-Escudero, J. A., \& Garcia, O. F. (2020). Parenting styles and their contribution to children personal and social adjustment. Anxiety and Stress, 26(1), 1-8. https://doi.org/10.1016/j. anyes.2019.12.001.

Wang, N., Chung, M. C., \& Wang, Y. (2020). The relationship between posttraumatic stress disorder, trauma centrality, posttraumatic growth and psychiatric co-morbidity among Chinese adolescents. Asian Journal of Psychiatry, 49, UNSP 101940. https://doi.org/10. 1016/j.ajp.2020.101940.

Widlund, A., Tuominen, H., Tapola, A., \& Korhonen, J. (2020). Gendered pathways from academic performance, motivational beliefs, and school burnout to adolescents' educational and occupational aspirations. Learning and Instruction, 66, 101299. https://doi. org/10.1016/j.learninstruc.2019.101299.

Wirthwein, L., Sparfeldt, J. R., Heyder, A., Buch, S., Rost, D. H., \& Steinmayr, R. (2020). Sex differences in achievement goals: Do school subjects matter? European Journal of Psychology of Education, 35(2), 403-427. https://doi.org/10.1007/s10212-01900427-7.

World Medical Association. (2009). Declaration of Helsinki. Ethical principles for medical research involving human subjets. JahrbuchFür Wissenschaft Und Ethik, 14, 233-238. https://doi.org/10.1515/ 9783110208856.233.

Wu, X., Zhang, J., Feng, H., \& Liu, Y. (2019). Research on the influence of physical education on healthy fitness based on physical selfconcept environment. Journal of Environmental Protection and Ecology, 20, 600-605.

Zamani-Alavijeh, F., Araban, M., Harandy, T. F., \& Bastami, F. (2019). Sources of health care providers ' self- efficacy to deliver health education : A qualitative study, 1-9.

Zhang, Z., Jiménez, F. R., \& Cicala, J. E. (2020). Fear of missing out scale: A self-concept perspective. Psychology \& Marketing, 37(11), 1619-1634. https://doi.org/10.1002/mar.21406.

Zurita-Ortega, F., González, C., Martínez-Martínez, A., Zafra-Santos, E. O., \& Valdivia-Moral, P. (2018a). Psychometric analysis and adaptation of the questionnaire AF5 towards judo in a Chilean sample. Universitas Psychologica, 17(4), 1-10. https://doi.org/10.11144/ javeriana.upsy 17-4.apat.

Zurita-Ortega, F., San Román-Mata, S., Martínez-Martínez, A., ChacónCuberos, R., Castro-Sánchez, M., \& Puertas-Molero, P. (2018b). Self-concept and religious tendency in university students: Psychometric properties of AF-5. Universitas Psychologica, 17(5), 1-12. https://doi.org/10.11144/javeriana.upsy17-5.atru.

Publisher's Note Springer Nature remains neutral with regard to jurisdictional claims in published maps and institutional affiliations. 